\title{
La dictadora en La dama de cristal, de Zelmar Acevedo Díaz ${ }^{1}$
}

\section{(The Dictator in La dama de cristal, by Zelmar Acevedo Díaz)}

\section{Elizabeth Abigail Sampson ${ }^{2}$}

The University of the West Indies, St. Augustine, Trinidad y Tobago

\section{resumen}

El estudio aborda el tema de la dictadora en La dama de cristal (1999), de Zelmar Acevedo Díaz (Argentina, 1951). Se comparan con otras novelas sobre el mismo tema y se examinan coincidencias o disparidades entre la representación literaria femenina y masculina del autoritarismo. La dictadura latinoamericana como fenómeno político ha persistido en América Latina con diferentes matices ideológicos. Gabriel García Márquez en $E l$ otoño del patriarca, Mario Vargas Llosa en La fiesta del Chivo o Luis Spota en El tiempo de la ira tratan este hecho para perfilar sus rasgos distintivos. Existe un caso particular en que el autoritarismo lo encarna una mujer.

\section{abstract}

This study focuses on the theme of female dictator in La dama de cristal (1999), by Zelmar Acevedo Díaz (Argentina, 1951). It is compared with other novels on the same theme and an analysis is carried out of coincidences or disparities between the feminine and masculine literary representation of authoritarianism. Latin American dictatorships are a political phenomenon that has persisted in Latin America with different ideological tones. Gabriel García Márquez in El otoño del patriarca; Mario Vargas Llosa in La fiesta del Chivo or Luis Spota in El tiempo de la ira have approached this issue to profile its distinctive features. There is one particular case of a female dictator.

1 Recibido: 2 de marzo de 2014; aceptado: 10 de abril de 2014.

2 Correo electrónico: elizsamp@yahoo.com, elizsamp@gmail.com

$$
L_{\text {etras }} 55 \text { (2014), ISSN 1409-424X; eISSN 2215-4094 }
$$


Palabras clave: novela hispanoamericana contemporánea, novela de la dictadura, narrativa argentina, narrativa nicaragüense

Keywords: contemporary Latin American novel, dictator novel, Argentinean narrative, Nicaraguan narrative

El proceso político de América Latina está marcado or la violencia, dictaduras y golpes de estado. Por lo general, los dictadores emplean medidas ilegítimas para llegar al poder. Aunque menos frecuente, algunos dictadores han utilizado medidas legítimas como elecciones libres y limpias para obtener el poder. En La dama de cristal, la dictadora no asume el poder gracias a las elecciones generales, sino por designación del Congreso. Hay preguntas sobre su legitimidad que emergen muy temprano. En ¿Te dio miedo la sangre?, de Sergio Ramírez, el dictador consigue el poder mediante las elecciones. Sin embargo, se desconoce si las elecciones fueron limpias y libres. El líder pone en marcha leyes para conservar el poder $^{3}$. Varios pasajes de ambas novelas tratan este asunto:

[...] la senadora Plaasumirá interinamentela presidencia de la Republica ${ }^{4}$.

[...] la legitimidad de la señora Pla está cuestionada si bien no legalmente, por lo menos en términos morales por la sencilla razón de que este gobierno, este modelo, este sistema, no fueron elegidos por nadie. La presidenta Pla recibió el poder por herencia, atravesando hechos penosos para la historia y la vida institucional de la nación (238).

[...] irreversiblemente la popularidad de la presidenta Eleonora Pla, cuyo gobierno, que no cuenta con legitimación electoral, aparece ahora en confrontación con un pueblo decidido a resistir el emplazamiento de una dictadura comunizante en ese país (347).

3 Es posible que el déspota, en El Señor Presidente, asuma el poder mediante elecciones. Los partidarios dicen que él es un presidente constitucional. Él busca la reelección. Hay muchas reformas que el Presidente quiere implementar para mejorar la calidad de vida de los ciudadanos y teme fracasar en las elecciones.

4 Zelmar Acevedo Díaz, La dama de cristal (La Habana: Casa de las Américas, 1999) 231. En adelante, las citas de la novela se consignan entre paréntesis. 
[...] los gruseos titulares de madera anunciaban el triunfo rotundo de el hombre en los limpios comicios supervigilados por observadores de La Unión Panamericana, y traían fotos del presidente reelecto 5 .

"El coronel [...] mandado por el hombre a hacer acto de presencia; venía la reelección de 1941, y quería aparecer bien con la religión ${ }^{6}$.

Existen otros líderes que emplean leyes y políticas para ejercer la dictadura. Muchas veces, el ejército está involucrado en los golpes de estado y cumple a cabalidad con las órdenes del tirano. El tirano ordena al ejército detener, torturar e interrogar a los prisioneros políticos.

Numerosos estudios tratan el tema; el de Alain Rouquié, Dictaduras y dictadores, sobresale, pues establece las características distintivas de los tiranos. José Mármol (Amalia), Heriberto Frías ( Tomochic!), Rufino Blanco Fombona (El hombre de hierro) y Pedro Jorge Vera (El pueblo soy yo) son ejemplos de algunos autores que han contribuido al tema. Una gran influencia entre los autores mencionados fue la de Tirano Banderas, de Ramón del Valle-Inclán. No obstante, el precursor de la novela de dictadura es Facundo, de Domingo Faustino Sarmiento. Según Julio Calviño Iglesias, en La novela del dictador en Hispanoamérica, estos escritores utilizaban las obras literarias para denunciar y cumplir una función axiológica? Este artículo pretende describir, desde una perspectiva novedosa, el perfil de una dictadora.

La palabra «dictador» ha sido empleada en términos generales por la crítica. Sin embargo, Ronald Wintrobe, en The Political Economy of Dictatorship, destaca cuatrotipos de dictadores: totalitarios, dictadores de pacotilla, tiranos y timócratas ${ }^{8}$. Los dictadores totalitarios dominan cada aspecto de la vida de los ciudadanos y ejecutan la represión más

5 Sergio Ramírez, ¿Te dio miedo la sangre? (Barcelona: Editorial Argos Vergara, 1983) 103.

6 Ramírez, 122.

7 Julio Calviño Iglesias, La novela del dictador en Hispanoamérica (Madrid: Instituto Iberoamericano de Cooperación, 1985).

8 Ronald Wintrobe, The Political Economy of Dictatorship (Nueva York: Cambridge University Press, 1998). 
extrema. Los dictadores de pacotilla establecen una represión modesta y su único objetivo consiste en utilizar el poder político para obtener ganancias. Este tipo de dictador suele tener un estilo de vida basado en el derroche. Según Wintrobe, la dinastía Somoza es emblemática de este segundo tipo de dictador.

Los tiranos son líderes que acuden a la represión intensa, pero no tienen acceso o no usan las herramientas de los medios de comunicación como lo hacen los totalitarios. La lealtad de los ciudadanos es muy baja. Según Wintrobe, los timócratas son dictadores generosos y demuestran interés por los ciudadanos, tanto en sus programas como políticas. La represión es baja y la lealtad de los ciudadanos es alta. La dictadora en La dama de cristal parece ser representativa de este último tipo. La dictadora se muestra menos opresiva que los dictadores de otras novelas como ¿Te dio miedo la sangre? y Ardillas enjauladas. El autor,Zelmar Acevedo Díaz, intenta destacar de manera más compasiva las acciones de la dictadora.

En La novela del dictador en Hispanoamérica, Calviño Iglesias completa una tarea excepcional, pues define las características clave de los dictadores. No todas las características son negativas. Algunos de los rasgos del dictador son el gansterismo, el afán de desfalco, el espíritu visionario y el carácter mesiánico ${ }^{9}$. Adicionalmente, Carlos Pacheco, en Narrativa de la dictadura y crítica literaria, presenta diecinueve características de los dictadores ${ }^{10}$. Estas particularidades incluyen el fondo social, las acciones y preocupaciones del dictador y la reacción de los ciudadanos hacia la represión. En este trabajo solo se emplean los aspectos de mayor pertinencia.

Eleonora, la protagonista de La dama de cristal, se entiende mediante múltiples perspectivas. En primer lugar, es una visionaria, pues si bien comenzó como profesora rural, pretendía contribuir al desarrollo de la Patagonia. Ve de primera mano las injusticias y la discriminación contra los ciudadanos rurales por parte del gobierno

9 Calviño Iglesias, 79.

10 Carlos Pacheco, Narrativa de la dictadura y crítica literaria (Caracas: Móvil-Libros, 1987). 
central. La aspiración de Eleonora es cambiar la manera en que se distribuyen los recursos.

Por otro lado, el dictador de ¿Te dio miedo la sangre? es un tirano; se presenta la perspectiva, el perfil y las preocupaciones masculinas del dictador. El dictador no tiene un nombre, se identifica solo como «el hombre» y se presenta más opresivo y sangriento que Eleonora en La dama de cristal. Claudia Schaefer, en el artículo titulado «La recuperación del realismo: ¿Te dio miedo la sangre? de Sergio Ramírez» afirma que «el hombre» es Anastacio Somoza y «los hijos del hombre» son Anastacio Somoza Debayle y Luis Somoza ${ }^{11}$. La tortura y la matanza de disidentes son ejemplos de su represión:

[...] en venganza le volvió a clavar el chuzo, «me vas a seguir engañando, mamplora de mierda», y el coronel, ocupado en el interrogatorio de otros prisioneros, lo oía gritar de dolor ante los chuzazos pero se hacía el sordo, como si no se hubieran visto nunca en la vida ${ }^{12}$.

Característica notable de Eleonora es su vocación mesiánica ${ }^{13}$; un propósito es salvar al país de desastre. Cuando ella era vicepresidenta, veía la corrupción del Presidente Montesinos. Eleonora quería limpiar al país, aunque esto implicara derrocar al Presidente. Asume el puesto tras ganar los votos de los miembros del Congreso ${ }^{14}$. Cumple

II Claudia Schaefer, «La recuperación del realismo: ¿Te dio miedo la sangre? de Sergio Ramírez» Texto Crítico XIII, 36-37 (1987): 146-152.

12 Ramírez, 68.

13 Como Eleonora Pla en La dama de cristal, el General Otte en ;A la orden, general Otte! es un mesías. Él desea remover la corrupción, caos y otros males de Parsimonia. En la novela, un ingeniero tiene un diálogo con un amigo y cree que él está predestinado a cumplir este propósito. Él habla de esta predestinación como el plan de Dios: mandar al General Otte a salvar Parsimonia. El General Otte recibe la adoración de los ciudadanos «[...] porque estamos convencidos que él es el hombre predestinado a salvar al país de la bancarrota, de la corrupción, de la anarquía y el abandono en que se halla por culpa de un gobierno de incapaces [...]» (Contreras Vélez, 1974, p.15-16). A diferencia de Eleonora Pla, el General Otte asume el poder mediante un golpe de Estado y luego, convoca elecciones.

14 Surgen opositores al General Otte: el doctor en pedagogía, Juan María Osuna, postulado por el Partido Civilista; el coronel Ignacio Durero, líder del Partido Reformista; y un tercer candidato por generación espontánea, Pompeyo Mazo, quien vino a ser la nota cómica del momento (Contreras Vélez, 1974, p. 41-42). 
sus promesas con los ciudadanos rurales: mejora la infraestructura de la escuela y brinda electricidad. Representa la novedad y la ruptura con el viejo orden ${ }^{15}$. «El hombre» no es un mesías. Según su representación, no es un salvador porque no trata de aliviar la pobreza, detener la violencia y remover los otros males que aquejan al país ${ }^{16}$. Este dictador es un villano.

En el fragmento citado, se plantea la preocupación de la protagonista por las partidas presupuestarias especiales, el comedor escolar modelo, el nuevo sistema de calefacción y lo más importante, la consecución de la energía eléctrica (121-122). En tanto figura literaria, Eleonora Pla personifica la esperanza. Los ciudadanos de la baja clase («los de abajo») anticipan un futuro mejor. Sin embargo, pronto las mujeres argentinas de la clase media y alta expresan su descontento respecto del estilo, ideas y políticas de la mandataria. Para ellas, Pla personifica un futuro siniestro; la ve como responsable del cercenamiento de su espacio y derecho a una vida de privilegios: «Llamarla comunista es mejor, pone las cosas en claro, evitamos equívocos» (273); «[...] la hija de Satanás» (312).

«El hombre» personifica la represión, es un líder absoluto. Los ciudadanos son incapaces de imaginarse un futuro mejor; él es más un impedimento que un recurso. El país no puede mejorar bajo su presidencia, pues ha infundido el miedo, la frustración y la hostilidad en la mente de los ciudadanos. A causa de ello, muchas personas quieren por cualquier medio derrocarlo. Los ciudadanos son pájaros

15 La persistencia de la mujer se presenta en la novela. Eleonora espera muchos días hablar con el gobernador de Patagonia sobre los problemas del pueblo rural. Ella trata de socavar las bases de la burocracia para mejorar la infraestructura de la escuela. Ella persigue el proceso de desarrollo de la escuela y el país: «Yo le pido ver al gobernador porque hay una escuela metida en medio de la Patagonia que pide calefacción y reparaciones, hay chicos que piden material didáctico y mejor alimentación, hay un pueblo que pide energía eléctrica, hay una tierra árida que pide un depósito de agua [...]. Señora, por favor, cálmese. ¿Usted cree que con ese tono va a lograr algo del gobernador? Mi paciencia y mi sonrisa de pasta dentífrica no parecen haber logrado mucho hasta ahora. Después de siete días consigo el privilegio de hablar con el secretario» (Acevedo Díaz, 119).

16 Varias fuentes como Un sol sobre Managua, Guardians of the Dynasty y Dictators Never Die: A Portrait of Nicaragua and the Somoza Dynasty apoyan esta perspectiva basada en la ambición, el nepotismo y la falta de preocupación ante las calamidades de los nicaragüenses. 
enjaulados que ansían oportunidades de volar y entonar cantos de libertad. Las actividades subversivas son el único medio de salvación ${ }^{17}$ : «Una convención de partidos opositores al régimen [...] discutiendo con alarde de manos sobre la forma de botar [sic] en unas elecciones limpias a la dictadura» ${ }^{18}$.

Eleonora reprime el derecho de libertad de expresión de los ciudadanos. Cuando los ciudadanos protestan contra sus políticas, ella recurre al ejército y la policía para arrestar a los ciudadanos que intentan desestabilizar el país o perturban la paz. La protesta es la forma de expresión que los ciudadanos utilizan para denunciar la gobernabilidad débil y la corrupción ${ }^{19}$. Eleonora disuelve el Parlamento Nacional y suspender las garantías constitucionales. Ella obra como un verdadero dictador, pues evita las elecciones limpias y libres. La represión es catalogada por un reportero de CNN como la más salvaje

17 Los ciudadanos, en ;A la orden de usted, General Otte!, ya no utilizan métodos simples para derrocar al General Otte. Un grupo rebelde quiere usar una bomba para desestabilizar al país y de hecho, desbancar al militar. La bomba es un método de escape de la represión: «Que el pueblo exija su renuncia y la de todos nosotros, y si no renunciamos, entonces irían a las armas y se lanzarían a la revolución» (Contreras Vélez, 96); «[...] hay que regar la especie de que el gobierno tomara tiránicas medidas para disolver esa manifestación» (Contreras Vélez, 97); «El régimen funesto del general Otte se ha excedido en sus abusos contra la libertad y los derechos humanos $[\ldots]$ » (Contreras Vélez, 104); «[...] la casta militar refuerza a los trogloditas y se crece y se agiganta en su despotismo» (Contreras Vélez, 104).

18 Ramírez, 39-40.

19 En la novela Ardillas enjauladas (Guatemala: Artemis, 1984), de Roberto Quezada, los ciudadanos protestan contra la opresión del dictador. Hay un grupo variopinto de manifestantes como ocurre en La dama de cristal (hombres, mujeres y niños). La mayoría de los ciudadanos, sin diferencias de edad y género, sufren la represión. En la protesta, una mujer y su bebé son asesinados por el ejército. Se da la utilización de fuerza excesiva aunque la protesta es tranquila, callada y los manifestantes carecen armas. El escritor usa una metáfora para describir a la muchedumbre, que compara con el mar: «La multitud era ya un mar de cabezas. Hombres, mujeres y niños» (Quezada, 38 ); «Sin otra arma que la furia en sus rostros, debían caminar lentamente, en silencio; los demás seguirían los pasos de los estudiantes y de esta manera, podrían enviar al tirano Ordóñez el signo de su descontento. Y aquí estaban estas mujeres, cambiando totalmente el objeto de la demostración. Serían unas cuarenta» (Quezada, 39); «Es el mar de los descontentos, de los oprimidos y de los soñadores" (Quezada, 40); «El niñito gritó una o dos veces, y luego se quedó silencioso. Una bala le había atravesado la cabeza, penetrando luego en el pecho de la madre, para luego quedarse alojada en su pulmón. Cayeron el suelo, unidos los dos cuerpos mientras la existencia se les escapaba lentamente» (Quezada, 45); «En la calle, los grupos se habían dispersado y todos corrían en distintas direcciones» (Quezada, 46) «[...] y sin embargo, el aire seguía calmado y puro. El cielo aún seguía azul y las nubes blancas. Pero ya no era difícil odiar o buscar la muerte» (Quezada, 47). 
y violenta en la historia del país, ya que el ejército agrede a los pacíficos manifestantes:

(CNN-Buenos Aires-Argentina) Un saldo de 14 muertos, un número no determinado de heridos y más de 100 detenidos fue el resultado de la represión más salvaje y violenta que registre la historia de ese país en los últimos cuarenta años (346).

-La señora nos comunica que el parlamento ha sido disuelto (411).

La suspención [sic] de las garantías constitucionales.

La restricción del funcionamiento del aparato jurídico.

La disolución del Parlamento Nacional (413).

En esta obra, se señala que el ejército desempeña los papeles de juez, torturador y verdugo. La dictadura no es sangrienta al modo del realismo gráfico de otras novelas acerca de la dictadura ${ }^{20}: \ll[\ldots]$ asesinato de un estudiante durante una manifestación de la Federación Universitaria que exigía del gobierno una profundización de la reforma agraria» (333).

En ¿Te dio miedo la sangre?, el dictador reprime los derechos de expresión y tránsito de los nicaragüenses ${ }^{21}$. Esta represión se extiende a los funerales también. Durante esta dictadura, los funerales no se celebran como en los regímenes democráticos. El funeral debe ser silencioso, porque puede ser un caldo de cultivo de los grupos clandestinos para planear su próximo ataque contra el dictador:

20 La dictador, Ardillas enjauladas, de Roberto Quezada, presenta la realidad de la represión militar: los ciudadanos muertos por motivo de las protestas pacíficas.

21 Ante el caos en Parsimonia, el General Otte responde con la ley marcial, lo que aumenta la represión. El autor, con un punto de vista satírico, retrata con humorismo los efectos de la ley marcial en los ciudadanos: «Parsimonia que desde que arreció la crisis parecía un cementerio, bajo la ley marcial parecía un cementerio sin muertos» (Contreras Vélez, 210); «Entonces sí que podía decirse que los negocios andaban mal. Hasta los mártires del amor libre -vulgo prostitutas- sufrieron mermas en la venta diaria» (Contreras Vélez, 211). Los disidentes son arrestados y acusados de subversión: «[...] la policía llevó a la cárcel a setenta y dos "protestantes" [...] previno a cinco periodistas independientes de que si seguían "haciéndole el juego a los conspiradores", la ley les sería aplicada con la severidad que la gravedad del caso ameritare, y expulsó del país a tres líderes radicales cristianos» (Contreras Vélez, 122). 
Dos días lo tuvieron con el cadáver en el puesto fronterizo del Espino Negro sin permitirle pasar, hasta tanto no llegaran órdenes de Managua [...] «Aquí solo valen las ordenes de el hijo del hombre» ${ }^{22}$.

«Ya tengo orden de que puede pasar su papa. Pero hay una condición: nada de aprovechar el entierro para alterar el orden público», golpeó con los dedos el telegrama, «y sobre todo, nada de discursos» ${ }^{23}$.

Además, «el hombre» prohíbe el despliegue del retrato de Liliana Rosales, concursante de la competencia señorita Nicaragua. Es una forma de control ideológico para cambiar el ideario político de los ciudadanos. Según Richard Millett, en Guardians of the Dynasty: «As long as the Somozas rule, however, the Guardia Nacional will remain not guardians of the Nicaraguan people, but rather the crucial and effective guardians of the dynasty» ${ }^{24}$. Esto se aprecia en la novela de Ramírez: «¡Viva Liliana Rosales, la candidata opositora! ¡Muera la dictadura! $\aleph^{25}$, «[...] ya fue delito andar el retrato de Liliana Rosales en la bolsa $[\ldots] »^{26}$.

El título de la novela, La dama de cristal, perfila a Eleonora. El escritor utiliza una metáfora para describirla: recuerda el vidrio, es una dama de cristal. Rompe la barrera de la desigualdad de género en el campo político, pues se convierte en líder del partido político y la nación. Pocas veces, otras novelas tratan acerca del tema de las mujeres en los puestos de poder; por lo general, las mujeres son presentadas como seres subordinados, sin importancia ni particularidades, son las personas de abajo y las amas de casa. Eleonora es preciosa y su fragilidad, como la del vidrio.

De la misma manera, el título de la otra novela, ¿Te dio miedo la sangre?, nos prepara ante el carácter del dictador. La palabra «sangre» personifica al dictador como un personaje violento. Sus acciones son

22 Ramírez, 171.

23 Ramírez, 176.

24 Richard Millett, Guardians of the Dynasty (Nueva York: Orbis Books, 1977) 261.

25 Ramírez, 126.

26 Ramírez, 127. 
cruentas y represivas, la sangre de sus enemigos fluye sin miedo de represalias. La sangre y la violencia permean la novela y avivan la tensión en el país representado. El título corrobora una característica clave de muchos dictadores, el empleo de la represión atroz:

Cuando la caravana llegó a Managua era ya de día, porque en otros puntos de la carretera iban deteniéndose para entrar a los cafetales a hacer otras ejecuciones de prisioneros ${ }^{27}$.

Con el poder y orgullo que esgrime el dictador, vienen la ansiedad y las preocupaciones principales de este tipo de personajes literarios: perpetuar el poder y consolidar la riqueza. Rouquié, en Dictaduras $y$ dictadores, corrobora este hecho en los ensayos de los escritores latinoamericanos: «[...] se preocupa fundamentalmente por su sobrevivencia, por la perennidad de su poderío, incluso de su riqueza $»^{28}$. En suma, el dictador, en tanto figura literaria, está delimitado por aspectos de carácter mítico, pero también realista. La manera en que el dictador aparece delineado depende del estilo o sesgo ideológico del novelista.

28 Alain Rouquié y otros, Dictaduras y dictadores (México: Universidad Nacional Autónoma de México, 1986) 19. 